\title{
Risk factors associated with ineligibility of adjuvant cisplatin-based chemotherapy after nephroureterectomy
}

This article was published in the following Dove Press journal:

Drug Design, Development and Therapy

2I October 2014

Number of times this article has been viewed

\author{
I-Hung Shao 1,2,* \\ Yu-Hsiang Lin ${ }^{1, *}$ \\ Chen-Pang Hou' \\ Horng-Heng Juang ${ }^{3,4}$ \\ Chien-Lun Chen' \\ Phei-Lang Chang ${ }^{1,4}$ \\ Ke-Hung Tsui ${ }^{1,4}$ \\ 'Department of Urology, Chang \\ Gung Memorial Hospital at Linkou, \\ Chang Gung University, ${ }^{2}$ Department \\ of Urology, Lotung Poh-Ai Hospital, \\ ${ }^{3}$ Department of Anatomy, Chang Gung \\ University, ${ }^{4}$ Bioinformation Center, \\ Chang Gung Memory Hospital, \\ Kwei-Shan, Tao-Yuan, Taiwan, \\ Republic of China \\ *These authors contributed equally \\ to this work
}

Purpose: Radical nephroureterectomy (RNU) is a standard treatment for upper urinary tract urothelial carcinoma. However, RNU can result in decreased renal function and cannot be treated with adjuvant chemotherapy. We performed a risk group stratification analysis to determine the preoperative factors that are predictive of diminished renal function after RNU.

Materials and methods: We retrospectively evaluated the medical records of all patients who underwent nephroureterectomy for upper urinary tract urothelial carcinoma at the Chang Gung Memorial Hospital from 2001 to 2008 . We analyzed the association between perioperative glomerular filtration rate and preoperative parameters including cancer characteristics, serum creatinine level, and kidney size measured on computed tomographic images.

Results: A total of 242 patients fulfilled the inclusion criteria. The average decrease in renal function 1 month after RNU was $19.7 \%$. Using $60 \mathrm{~mL} / \mathrm{min} / 1.73 \mathrm{~m}^{2}$ as the eligibility cutoff for cisplatin-based chemotherapy, $42.1 \%$ of the population was eligible prior to nephroureterectomy, whereas following surgery only $15.2 \%$ remained eligible. Using a cutoff of $45 \mathrm{~mL} / \mathrm{min} / 1.73 \mathrm{~m}^{2}$, $59.9 \%$ of the cohort was eligible for fractionated cisplatin dosing preoperatively, whereas only $32.6 \%$ remained above the cutoff postoperatively. The most significant predictors of poor postoperative renal function were body mass index $>25 \mathrm{~kg} / \mathrm{m}^{2}$, age $>65$ years, contralateral kidney length less than $10 \mathrm{~cm}$, and absence of ipsilateral hydronephrosis.

Conclusion: Our results suggest that older age, higher body mass index, smaller contralateral renal length, and absence of ipsilateral hydronephrosis are predictive of decreased renal function after RNU.

Keywords: transitional cell, carcinoma, kidney, adjuvant chemotherapy, upper tract urothelial carcinoma

\section{Introduction}

Upper urinary tract (UUT) urothelial carcinoma (UC) is a relatively rare tumor, accounting for only $5 \%-10 \%$ of all renal tumors and $5 \%-6 \%$ of urothelial tumors. ${ }^{1-3}$

Radical nephroureterectomy (RNU) with bladder cuff excision remains the standard treatment of upper-tract urinary urothelial carcinoma. ${ }^{4}$ Although RNU with bladder cuff excision is a very effective treatment for organ-confined UUT-UC, it results in less than optimal outcome for patients with nodal and distant metastatic disease. . $^{3,5,6}$

The 5-year cancer-specific survival rate has been reported to be $>90 \%$ for patients with stage pT1 UUT-UC; however, the survival rate for patients with pT3 stage disease is lower than $50 \% .^{7}$ Adjuvant chemotherapy is an effective treatment modality for the high tumor staging and local advanced urothelial carcinoma. ${ }^{8}$ Neoadjuvant chemotherapy before radical cystectomy has been reported to have a survival benefit
Correspondence: Ke-Hung Tsui

Department of Urology, Chang Gung Memorial Hospital-Linkou

5 Fu-Shing Street, Kweishan,

Taoyuan, 333, Taiwan, Republic of China

Tel +0II 886332812002137

Fax+0II 886227358775

Email khtsui@yahoo.com 
for patients with bladder urothelial carcinoma. ${ }^{9,10}$ However, few studies have shown a survival benefit for neoadjuvant chemotherapy before RNU of the UC. ${ }^{11,12}$

Although neoadjuvant chemotherapy before RNU has been performed in more and more patients, it is not the standard procedure yet. Taken together, it is known that radical nephrectomy can result in decreased renal function in patients with renal cell cortical tumors. ${ }^{13}$ The same condition has been observed in patients with upper urinary tract urothelial carcinomas after RNU, and that deteriorated renal function may interfere with adjuvant chemotherapy.

We aimed to clarify the relationship between RNU and postoperative renal function in patients with upper urinary tract urothelial carcinoma. We also wanted to find out if there is an adequate predictor for marked post-RNU renal function deterioration.

\section{Materials and methods}

We retrospectively reviewed the medical charts of patients with upper urinary tract urothelial carcinoma who received RNU from 2001 to 2008. Data of interest included patient characteristics (age at surgery, sex, body height, body weight, body mass index [BMI], and underlying disease), cancer characteristics (tumor location, tumor stage based on the seventh edition American Joint Committee on Cancer criteria, pathological grade, and tumor histology), serum creatinine level (pre-operation and 1-month post-operation), and kidney size on computed tomographic images (largest kidney length and width on coronal view, and parenchymal thickness).

Renal estimated glomerular filtration rate (eGFR) was calculated using the abbreviated Modification of Diet in Renal Disease equation:

$$
\mathrm{eGFR}=186 \times(\text { serum creatinine })^{-1.154} \times(\text { age })^{-0.203}
$$

multiplied by 0.742 for female patients and by 1.212 for male patients. ${ }^{14}$

eGFR before and after surgery was compared using serum creatinine drawn closest to 1 month after surgery (range: 4 weeks to 6 weeks after surgery). This timing was selected to best approximate the measured serum creatinine that would affect the delivery of adjuvant chemotherapy. We excluded patients with incomplete medical records, end-stage renal disease under hemodialysis or bilateral disease, and patients who had previously received neoadjuvant chemotherapy or other treatment modalities that could potentially influence renal function.
We used binary logistic regression to assess the correlation of each factor with decreased renal function (45 and $60 \mathrm{~mL} / \mathrm{min} / 1.73 \mathrm{~m}^{2}$ ). We also calculated the odds ratio of each predictor of ineligibility for adjuvant chemotherapy after RNU. Multivariate analysis was performed to find the most significant predictors.

All statistical calculations were two-tailed, and $P<0.05$ was deemed significant. SPSS version 17 (SPSS Inc., Chicago, IL, USA) was used for all statistical analysis.

\section{Results}

A total of 242 patients fulfilled the criteria for analysis. The median age at surgery was 71 years (range, 42-83 years) and the male-to-female ratio was 1.08 (126 versus 116). Other patient characteristics are listed in Table 1.

The mean eGFR before RNU was $56.9 \pm 19.6 \mathrm{~mL} /$ $\min / 1.73 \mathrm{~m}^{2}$, while mean postoperative eGFR was $45.7 \pm 16.6$ $\mathrm{mL} / \mathrm{min} / 1.73 \mathrm{~m}^{2}$. The average renal function decrease

Table I Clinicopathological characteristics of the 242 study patients

\begin{tabular}{|c|c|}
\hline \multicolumn{2}{|l|}{ Age, years } \\
\hline Median (range) & $71.0(42-83)$ \\
\hline \multicolumn{2}{|l|}{ Sex, n (\%) } \\
\hline Male & $126(52)$ \\
\hline Female & I I 6 (48) \\
\hline \multicolumn{2}{|l|}{ Body mass index, $\mathrm{kg} / \mathrm{m}^{2}$} \\
\hline Median (IQR) & $25.10(13-37)$ \\
\hline \multicolumn{2}{|l|}{ Primary tumor location, n (\%) } \\
\hline Renal pelvis & $152(63)$ \\
\hline Ureteral & $90(37)$ \\
\hline \multicolumn{2}{|l|}{ Surgical approach, n (\%) } \\
\hline Open & $162(63)$ \\
\hline Laparoscopic & $80(22)$ \\
\hline \multicolumn{2}{|l|}{ Tumor histology, n (\%) } \\
\hline Papillary & $17(6.9)$ \\
\hline Infiltrating & $225(93.1)$ \\
\hline \multicolumn{2}{|l|}{ PT stage, n (\%) } \\
\hline PTa-pTis-pTI & $65(26.8)$ \\
\hline pT2 & $43(17.8)$ \\
\hline pT3 & $87(36.1)$ \\
\hline pT4 & $47(19.3)$ \\
\hline \multicolumn{2}{|l|}{ Lymph node status, n (\%) } \\
\hline $\mathrm{pN} 0$ & $212(87.7)$ \\
\hline $\mathrm{pN}+$ & $30(12.3)$ \\
\hline \multicolumn{2}{|l|}{ M stage, n (\%) } \\
\hline pMO & $232(96.0)$ \\
\hline pMI & $10(4.0)$ \\
\hline \multicolumn{2}{|l|}{ Contralateral kidney size, $\mathrm{cm}$} \\
\hline Length, median (range) & $10.16(7.0-12.8)$ \\
\hline Width, median (range) & $5.1(3.8-6.9)$ \\
\hline Thickness, median (range) & $2.0(1.2-2.3)$ \\
\hline
\end{tabular}

Abbreviations: IQR, interquartile range; $M$ stage, metastasis stage; $P T$ stage, primary tumor stage. 
1 month after RNU was $19.7 \%$ and the average renal function decrease 2 years after surgery was $22.1 \%$. Of the 242 patients, $102(42.1 \%)$ had a preoperative eGFR $\geq 60 \mathrm{~mL} / \mathrm{min} / 1.73 \mathrm{~m}^{2}$ and 145 (59.9\%) had an eGFR $\geq 45 \mathrm{~mL} / \mathrm{min} / 1.73 \mathrm{~m}^{2}$.

Using $60 \mathrm{~mL} / \mathrm{min} / 1.73 \mathrm{~m}^{2}$ as the eligibility cutoff for cisplatin-based chemotherapy, $42.1 \%$ of the population was eligible prior to nephroureterectomy, whereas following surgery only $15.2 \%$ remained eligible. Using a cutoff of $45 \mathrm{~mL} / \mathrm{min} / 1.73 \mathrm{~m}^{2}, 59.9 \%$ of the cohort was eligible for fractionated cisplatin dosing preoperatively, whereas only $32.6 \%$ remained above the cutoff postoperatively.

Using $60 \mathrm{~mL} / \mathrm{min} / 1.73 \mathrm{~m}^{2}$ as the cutoff, we analyzed the correlation and odds ratio of possible predictors. The significant factors were age at operation, BMI, preoperative eGFR, history of hypertension, contralateral kidney size, and ipsilateral hydronephrosis. The detailed data including other factors are listed in Table 2.

Using $45 \mathrm{~mL} / \mathrm{min} / 1.73 \mathrm{~m}^{2}$ as the cutoff, the significant predictors were BMI, preoperative serum creatinine level, preoperative eGFR, tumor stage, contralateral kidney size, and ipsilateral hydronephrosis. Other factors and detailed results are listed in Table 3.

We performed multivariate analyses to define the most significant predictors. We found that patients with younger age, lower BMI, larger contralateral renal length, and ipsilateral hydronephrosis were more likely to remain

Table 2 Clinicopathological characteristics of 102 patients who met the eligibility cutoff of $60 \mathrm{~mL} / \mathrm{min} / 1.73 \mathrm{~m}{ }^{2}$ for cisplatin-based chemotherapy

\begin{tabular}{|c|c|c|c|c|c|c|c|}
\hline Characteristics & Total $(n=102)$ & $(n=37)$ eGFR & $(n=65)$ eGFR & Sig & OR & $95 \% \mathrm{C}$ & for OR \\
\hline & & & & & & & \\
\hline 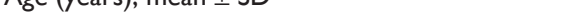 & $03.82 \pm 10.9$ & 03.0113 .2 & & 0.001 & & & \\
\hline Sex, $n$ & & & & & & & \\
\hline Male & 57 & 26 & 31 & 0.029 & 2.592 & 1.101 & 6.103 \\
\hline Female & 45 & 11 & 34 & & & & \\
\hline $\mathrm{BMI}\left(\mathrm{kg} / \mathrm{m}^{2}\right)$, mean $\pm \mathrm{SD}$ & $24.7 \pm 4.5$ & $21.56 \pm 4.79$ & $26.47 \pm 3.25$ & $<0.001$ & $\mathrm{I} .58 \mathrm{I}$ & 1.261 & 1.981 \\
\hline Preoperative Scr $(\mathrm{mg} / \mathrm{dL})$, mean $\pm \mathrm{SD}$ & $0.99 \pm 0.16$ & $0.96 \pm 0.19$ & $1.00 \pm 0.15$ & 0.236 & 4.645 & 0.366 & 58.984 \\
\hline Preoperative eGFR $\left(\mathrm{mL} / \mathrm{min} / 1.73 \mathrm{~m}^{2}\right)$, mean $\pm \mathrm{SD}$ & $71.97 \pm 11.3$ & $79.78 \pm 13.5$ & $68.84 \pm 6.7$ & $<0.001$ & 0.892 & 0.845 & 0.942 \\
\hline History of diabetes, $\mathrm{n}$ & & & & & & & \\
\hline Yes & 22 & 6 & 16 & 0.325 & 1.687 & 0.596 & 4.776 \\
\hline No & 80 & 31 & 49 & & & & \\
\hline History of HT, $n$ & & & & & & & \\
\hline Yes & 33 & 6 & 27 & 0.011 & 3.671 & 1.345 & 10.017 \\
\hline No & 69 & 31 & 38 & & & & \\
\hline Tumor characteristics & & & & & & & \\
\hline Tumor histology, n & & & & & & & \\
\hline Papillary & 6 & 4 & 2 & 0.133 & 3.818 & 0.664 & 21.947 \\
\hline Infiltrating & 96 & 33 & 63 & & & & \\
\hline Tumor side, $\mathrm{n}$ & & & & & & & \\
\hline Left & 74 & 21 & 30 & 0.304 & 0.653 & 0.29 & 1.472 \\
\hline Right & 71 & 16 & 35 & & & & \\
\hline Tumor stage, $\mathrm{n}$ & & & & & & & \\
\hline $\mathrm{TI}+\mathrm{Ta}$ & 23 & 8 & 15 & $0.74 I$ & 0.938 & $0.64 I$ & 1.372 \\
\hline $\mathrm{T} 2$ & 20 & 4 & 16 & & & & \\
\hline T3 & 33 & 16 & 17 & & & & \\
\hline $\mathrm{T} 4$ & 26 & 9 & 17 & & & & \\
\hline Node status, $n$ & & & & & & & \\
\hline No & 91 & 30 & 61 & 0.056 & $0.28 \mathrm{I}$ & 0.076 & 1.035 \\
\hline $\mathrm{N}+$ & II & 7 & 4 & & & & \\
\hline Contralateral kidney size $(\mathrm{cm})$, mean $\pm S D$ & & & & & & & \\
\hline Length & $10.50 \pm 1.1$ & $11.21 \pm 0.89$ & $10.1 \pm 1.0$ & $<0.001$ & 0.342 & 0.212 & 0.553 \\
\hline Width & $5.13 \pm 1.12$ & $5.59 \pm 0.7$ & $4.86 \pm 1.24$ & 0.003 & 0.448 & 0.265 & 0.756 \\
\hline Thickness & $0.7 I \pm 0.09$ & $0.75 \pm 0.08$ & $0.69 \pm 0.09$ & 0.002 & 0 & 0 & 0.05 \\
\hline Hydronephrosis, $n$ & & & & & & & \\
\hline Yes & 77 & 34 & 43 & 0.007 & 0.172 & 0.048 & 0.625 \\
\hline No & 25 & 3 & 22 & & & & \\
\hline
\end{tabular}

Abbreviations: BMI, body mass index; $\mathrm{Cl}$, confidence interval; eGFR, estimated glomerular filtration rate; HT, hypertension; OR, odds ratio; Scr, serum creatinine level; SD, standard deviation; Sig, P-value. 
Table 3 Clinicopathological characteristics of 145 patients who met the eligibility cutoff of $45 \mathrm{~mL} / \mathrm{min} / \mathrm{I} .73 \mathrm{~m} \mathrm{~m}^{2}$ for cisplatin-based chemotherapy

\begin{tabular}{|c|c|c|c|c|c|c|c|}
\hline \multirow{2}{*}{$\begin{array}{l}\text { Characteristics } \\
\text { Age (years), mean } \pm \text { SD }\end{array}$} & \multirow{2}{*}{$\begin{array}{l}\begin{array}{l}\text { Total } \\
(n=145)\end{array} \\
66.9 \pm 10.1\end{array}$} & \multirow{2}{*}{$\begin{array}{l}(\mathrm{n}=102) \\
\text { eGFR } \geqq 45 \mathrm{~mL} / \mathrm{min} \\
66.82 \pm 10.8\end{array}$} & \multirow{2}{*}{$\begin{array}{l}(\mathrm{n}=43) \text { eGFR } \\
<45 \mathrm{~mL} / \mathrm{min} \\
68.0 \pm 10.0\end{array}$} & \multirow{2}{*}{$\begin{array}{l}\text { Sig } \\
0.754\end{array}$} & \multirow{2}{*}{$\begin{array}{l}\text { OR } \\
1.006\end{array}$} & \multicolumn{2}{|c|}{$95 \% \mathrm{Cl}$ for OR } \\
\hline & & & & & & $0.97 \mid$ & 1.042 \\
\hline \multicolumn{8}{|l|}{ Sex, $n$} \\
\hline Male & $74(51.0)$ & $47(67.1)$ & 27 & 0.068 & 0.506 & 0.244 & 1.052 \\
\hline Female & 7I (49.0) & $55(66.2)$ & 16 & & & & \\
\hline $\mathrm{BMI}, \mathrm{kg} / \mathrm{m}^{2}$, mean $\pm \mathrm{SD}$ & $24.5 I \pm 4.54$ & $23.48 \pm 4.40$ & $26.97 \pm 3.90$ & $<0.001$ & 1.243 & 1.111 & 1.391 \\
\hline $\mathrm{Scr}, \mathrm{mg} / \mathrm{dL}$, mean $\pm \mathrm{SD}$ & $1.06 \pm 0.193$ & $1.00 \pm 0.166$ & $1.19 \pm 0.19$ & $<0.00$ I & 493.082 & 36.913 & $6,586.62$ \\
\hline eGFR, $\mathrm{mL} / \mathrm{min}$, mean $\pm \mathrm{SD}$ & $66.59 \pm 13.5$ & $69.59 \pm 14.0$ & $59.48 \pm 8.83$ & $<0.001$ & 0.927 & 0.892 & 0.962 \\
\hline \multicolumn{8}{|l|}{ History of diabetes, $\mathrm{n}$} \\
\hline Yes & 35 & 28 & 7 & 0.156 & 0.514 & 0.205 & 1.288 \\
\hline No & 110 & 74 & 36 & & & & \\
\hline \multicolumn{8}{|l|}{ History of $H T, n$} \\
\hline Yes & 61 & 45 & 16 & 0.442 & $0.75 \mathrm{I}$ & 0.361 & 1.56 \\
\hline No & 84 & 57 & 27 & & & & \\
\hline \multicolumn{8}{|l|}{ Tumor characteristics } \\
\hline \multicolumn{8}{|l|}{ Tumor histology, $\mathrm{n}$} \\
\hline Papillary & 10 & 6 & 4 & 0.462 & 0.609 & 0.163 & 2.278 \\
\hline Infiltrating & 135 & 96 & 39 & & & & \\
\hline \multicolumn{8}{|l|}{ Tumor side, $\mathrm{n}$} \\
\hline Left & 74 & 51 & 23 & 0.701 & 1.15 & 0.563 & 2.348 \\
\hline Right & 7I & 51 & 20 & & & & \\
\hline \multicolumn{8}{|l|}{ Tumor stage, $\mathrm{n}$} \\
\hline $\mathrm{TI}+\mathrm{Ta}$ & 38 & 14 & 24 & $<0.001$ & 0.335 & 0.222 & 0.505 \\
\hline $\mathrm{T} 2$ & 25 & 20 & 5 & & & & \\
\hline T3 & 48 & 34 & 14 & & & & \\
\hline T4 & 34 & 34 & 0 & & & & \\
\hline \multicolumn{8}{|l|}{ Node status, $\mathrm{n}$} \\
\hline No & 134 & 95 & 39 & 0.614 & 1.392 & 0.386 & 5.025 \\
\hline $\mathrm{N}+$ & 11 & 7 & 4 & & & & \\
\hline \multicolumn{8}{|c|}{ Contralateral kidney size $(\mathrm{cm})$, mean $\pm \mathrm{SD}$} \\
\hline Length & $10.42 \pm 0.99$ & $10.6 \pm 1.06$ & $9.9 \pm 0.56$ & $<0.001$ & 0.399 & $0.24 I$ & 0.66 \\
\hline Width & $5.12 \pm 1.00$ & $5.4 \pm 0.82$ & $4.57 \pm 1.17$ & $<0.001$ & 0.386 & 0.229 & 0.651 \\
\hline Thickness & $0.70 \pm 0.09$ & $0.73 \pm 0.09$ & $0.64 \pm 0.76$ & $<0.001$ & 0.001 & 0 & 0.002 \\
\hline \multicolumn{8}{|l|}{ Hydronephrosis, n } \\
\hline Yes & 107 & 83 & 24 & 0.002 & 0.289 & 0.132 & 0.632 \\
\hline No & 38 & 19 & 19 & & & & \\
\hline
\end{tabular}

Abbreviations: $\mathrm{BMI}$, body mass index; $\mathrm{Cl}$, confidence interval; eGFR, estimated glomerular filtration rate; $\mathrm{HT}$, hypertension; OR, odds ratio; Scr, serum creatinine level; $\mathrm{SD}$, standard deviation; Sig, P-value.

eligible for full-dose cisplatin-based chemotherapy after the surgery. When an eGFR value of $45 \mathrm{~mL} / \mathrm{min} / 1.73 \mathrm{~m}^{2}$ was used as the cutoff point, we found that all of those variables, with the exception of age, remained significant predictors (Table 4).

Receiver operating characteristic curve analysis revealed that $\mathrm{BMI}>25 \mathrm{~kg} / \mathrm{m}^{2}$, age $>65$ years, and contralateral kidney length $<10 \mathrm{~cm}$ were the most significant predictors of poor postoperative renal function.

\section{Discussion}

The prognosis of upper urinary tract urothelial cell carcinoma has been shown to be significantly related to tumor stage. ${ }^{15}$
Margulis et al reported that the 5-year survival rates of patients with positive lymph nodes were $35.3 \%$ for patients with pT2 disease, $74.7 \%$ for patients with pT3 disease, and $54 \%$ for those with pT4 disease. ${ }^{7}$ Of the patients with upper urinary tract urothelial carcinoma, patients with pathologic stage T2 or higher accounted for more than half of the evaluated patients. ${ }^{7}$ Based on the abovementioned evidence, RNU alone may be sufficient for localized upper urinary tract urothelial carcinoma. For patients with locally advanced disease or high tumor staging and suspicious metastatic disease, multimodal therapy may be required for better outcome.

There are conflicting data regarding the efficacy of adjuvant chemotherapy for locally advanced disease and 
Table 4 Multivariate analysis of preoperative variables for disease-specific survival

\begin{tabular}{|c|c|c|c|c|}
\hline & $P$-value & OR & $(95 \%$ & \\
\hline \multicolumn{5}{|l|}{ Post-eGFR $<60$} \\
\hline Age & 0.007 & 1.987 & 1.204 & 3.279 \\
\hline BMI & 0.005 & 10.392 & 2.046 & 52.788 \\
\hline Preoperative eGFR & 0.002 & 0.554 & 0.385 & 0.798 \\
\hline Contralateral renal length & 0.012 & 0.012 & 0.000 & 0.386 \\
\hline Hydronephrosis & 0.011 & 0.000 & 0.000 & 0.065 \\
\hline \multicolumn{5}{|l|}{ Post-eGFR $<45$} \\
\hline BMI & $<0.001$ & 1.493259 & 1.243 & 1.793 \\
\hline Preoperative eGFR & $<0.001$ & 0.8396842 & 0.769 & 0.916 \\
\hline Contralateral renal length & 0.064 & 0.346669 & 0.113 & 1.063 \\
\hline Contralateral renal width & 0.010 & 0.3749981 & 0.178 & 0.788 \\
\hline Contralateral renal thickness & 0.055 & 0.1191959 & 0.014 & 1.050 \\
\hline Hydronephrosis & $<0.001$ & 0.0476294 & 0.010 & 0.235 \\
\hline
\end{tabular}

Abbreviations: $\mathrm{BMI}$, body mass index; $\mathrm{Cl}$, confidence interval; eGFR, estimated glomerular filtration rate; OR, odds ratio.

metastatic disease. Hellenthal et al and Vassilakopoulou et al reported that systemic adjuvant chemotherapy is not beneficial. ${ }^{16,17}$ As for neoadjuvant chemotherapy, Matin et al and Rajput et al reported that systemic neoadjuvant chemotherapy could achieve a complete remission (pT0) rate of $15 \%,{ }^{11,12}$ and some studies have also reported that neoadjuvant chemotherapy improves overall survival. ${ }^{10,11,16,17}$ Considering the established effect of neoadjuvant chemotherapy in bladder urothelial cell carcinoma, cisplatin-based chemotherapy may be more effective than neoadjuvant therapy for upper urinary tract urothelial cell carcinoma. ${ }^{10,17}$

On the other hand, cisplatin-based chemotherapy requires adequate renal function, which may decrease after RNU. ${ }^{18-23}$ Thus, neoadjuvant cisplatin-based chemotherapy might be a more appropriate treatment for patients with locally advanced or metastatic upper urinary tract urothelial cell carcinoma.

In our study, we set the cutoff points for renal function as an eGFR of $60 \mathrm{~mL} / \mathrm{min} / 1.73 \mathrm{~m}^{2}$ and $45 \mathrm{~mL} / \mathrm{min} / 1.73$ $\mathrm{m}^{2}$. An eGFR value of $60 \mathrm{~mL} / \mathrm{min} / 1.73 \mathrm{~m}^{2}$ is used to define eligibility for full-dose cisplatin therapy and also represents the transition into stage III chronic kidney disease, while $45 \mathrm{~mL} / \mathrm{min} / 1.73 \mathrm{~m}^{2}$ may be a compromise between the eGFR of $40 \mathrm{~mL} / \mathrm{min} / 1.73 \mathrm{~m}^{2}$ that was used as the lower limit to exclude patients for reduced-dose cisplatin by Hussain et al and the eGFR of $50-55 \mathrm{~mL} / \mathrm{min} / 1.73 \mathrm{~m}^{2}$ that has been used in several European studies to qualify patients as ineligible for cisplatin. ${ }^{23,24}$

According to our findings as well as those published previously, $37 \%-49 \%$ of patients had a preoperative eGFR of more than $60 \mathrm{~mL} / \mathrm{min} / 1.73 \mathrm{~m}^{2}$, making them eligible for fulldose cispatin-based chemotherapy. The percentage decreased to $19 \%$ after RNU. At a cutoff of $45 \mathrm{~mL} / \mathrm{min} / 1.73 \mathrm{~m}^{2}$, the number of patients eligible for cispatin-based chemotherapy decreased from $60 \%-80 \%$ to $33 \%-55 \%{ }^{23-26}$

A number of studies have reported similar findings, namely that a decrease in postoperative eGFR may hinder the use of neoadjuvant chemotherapy and possibly result in poor outcome. Neoadjuvant chemotherapy, therefore, should be prompted in select high-risk patients who may experience significant renal function deterioration after the operation.

In our study, we found that patients $>65$ years, patients with a BMI $>25 \mathrm{~kg} / \mathrm{m}^{2}$, patients with a contralateral kidney length $<10 \mathrm{~cm}$, and patients without ipsilateral hydronephrosis are at significant risk of decreased renal function after surgery. In that group, patients with a disease stage of T2 or higher and patients with metastatic disease should undergo neoadjuvant chemotherapy rather than adjuvant chemotherapy.

It is assumed that in elderly patients and patients with higher BMI, the remnant kidney may barely support the physical need, making it easy to fail under stress.

Besides, in the patients who had unilateral disease and suffered from obstructive uropathy before RNU, the other healthier kidney accounted for more renal function. This means that the post-RNU renal function would be closer to the pre-RNU renal function. That is why we found that patients with ipsilateral hydronephrosis and larger contralateral kidney would had less renal function loss after the surgery.

Our study is limited by its retrospective nature and by the small number of patients included for analysis. In addition, renal size or cortical thickness does not accurately represent the renal function of the remnant kidney. Renograms may 
offer more information. A prospective study with a larger sample size is needed to confirm our findings.

\section{Conclusion}

In our study, only some of the patients with upper urinary tract urothelial cell carcinoma were eligible for cisplatin-based chemotherapy, and this proportion decreased significantly after RNU. To increase survival outcome, patients of advanced age, those with higher BMI values, patients with smaller contralateral renal length, and patients without evidence of ipsilateral hydronephrosis are likely to develop renal insufficiency after surgery and should be treated with neoadjuvant chemotherapy.

\section{Acknowledgments}

We thank Y-L Tsai for the biostatistical study. This research was supported by grants from the Chang Gung Memorial Hospital (CMRP-G392163, -G3B1892, -G392143, and -G3B1891) and the National Science Council, Taiwan, (NSC 101-2320-B-182-002 and NSC 101-2314-B-182A099-MY3).

\section{Disclosure}

The authors report no conflicts of interest in this work.

\section{References}

1. Krogh J, Kvist E, Rye B. Transitional cell carcinoma of the upper urinary tract: prognostic variables and post-operative recurrences. Br J Urol. 1991;67(1):32-36.

2. Hall MC, Womack S, Sagalowsky AI, Carmody T, Erickstad MD, Roehrborn CG. Prognostic factors, recurrence, and survival in transitional cell carcinoma of the upper urinary tract: a 30-year experience in 252 patients. Urology. 1998;52(4):594-601.

3. Huben RP, Mounzer AM, Murphy GP. Tumor grade and stage as prognostic variables in upper tract urothelial tumors. Cancer. 1988;62(9):2016-2020.

4. Raman JD, Scherr DS. Management of patients with upper urinary tract transitional cell carcinoma. Nat Clin Pract Urol. 2007;4(8):432-443.

5. Racioppi M, D’Addessi A, Alcini A, Destito A, Alcini E. Clinical review of 100 consecutive surgically treated patients with upper urinary tract transitional tumours. Br J Urol. 1997;80(5):707-711.

6. Langner C, Hutterer G, Chromecki T, Leibl S, Rehak P, Zigeuner R. Tumor necrosis as prognostic indicator in transitional cell carcinoma of the upper urinary tract. $J$ Urol. 2006;176(3):910-913; discussion 913-914.

7. Margulis V, Shariat SF, Matin SF, et al; Upper Tract Urothelial Carcinoma Collaboration The Upper Tract Urothelial Carcinoma Collaboration. Outcomes of radical nephroureterectomy: a series from the Upper Tract Urothelial Carcinoma Collaboration. Cancer. 2009;115(6):1224-1233.

8. Yagoda A. Chemotherapy of urothelial tract tumors. Cancer. 1987;60(3 Suppl):574-585.

9. Grossman HB, Natale RB, Tangen CM, et al. Neoadjuvant chemotherapy plus cystectomy compared with cystectomy alone for locally advanced bladder cancer. N Engl J Med. 2003;349(9):859-866.
10. Advanced Bladder Cancer (ABC) Meta-analysis Collaboration. Neoadjuvant chemotherapy in invasive bladder cancer: update of a systematic review and meta-analysis of individual patient data advanced bladder cancer (ABC) meta-analysis collaboration. Eur Urol. 2005;48(2):202-205; discussion 205-206.

11. Matin SF, Margulis V, Kamat A, et al. Incidence of downstaging and complete remission after neoadjuvant chemotherapy for highrisk upper tract transitional cell carcinoma. Cancer. 2010;116(13): 3127-3134.

12. Rajput MZ, Kamat AM, Clavell-Hernandez J, et al. Perioperative outcomes of laparoscopic radical nephroureterectomy and regional lymphadenectomy in patients with upper urinary tract urothelial carcinoma after neoadjuvant chemotherapy. Urology. 2011;78(1):61-67.

13. Huang WC, Levey AS, Serio AM, et al. Chronic kidney disease after nephrectomy in patients with renal cortical tumours: a retrospective cohort study. Lancet Oncol. 2006;7(9):735-740.

14. Levey AS, Bosch JP, Lewis JB, Greene T, Rogers N, Roth D. A more accurate method to estimate glomerular filtration rate from serum creatinine: a new prediction equation. Modification of Diet in Renal Disease Study Group. Ann Intern Med. 1999;130(6):461-470.

15. Png KS, Lim EK, Chong KT, Sugiono M, Yip SK, Cheng CW. Prognostic factors for upper tract transitional cell carcinoma: a retrospective review of 66 patients. Asian J Surg. 2008;31(1):20-24.

16. Hou CP, Lin YH, Chen CL, Chang PL, Tsui KH. Clinical outcome of primary small cell carcinoma of the urinary bladder. Onco Targets Ther. 2013;6:1179-1185.

17. Chromecki TF, Bensalah K, Remzi M, et al. Prognostic factors for upper urinary tract urothelial carcinoma. Nat Rev Urol. 2011;8(8):440-447.

18. Kwak C, Lee SE, Jeong IG, Ku JH. Adjuvant systemic chemotherapy in the treatment of patients with invasive transitional cell carcinoma of the upper urinary tract. Urology. 2006;68(1):53-57.

19. Hellenthal NJ, Shariat SF, Margulis V, et al. Adjuvant chemotherapy for high risk upper tract urothelial carcinoma: results from the Upper Tract Urothelial Carcinoma Collaboration. J Urol. 2009;182(3):900-906.

20. Vassilakopoulou M, de la Motte Rouge T, Colin P, et al; French Collaborative National Database on UUT-UCC. Outcomes after adjuvant chemotherapy in the treatment of high-risk urothelial carcinoma of the upper urinary tract (UUT-UC): results from a large multicenter collaborative study. Cancer. 2011;117(24):5500-5508.

21. Advanced Bladder Cancer (ABC) Meta-analysis Collaboration. Adjuvant chemotherapy in invasive bladder cancer: a systematic review and meta-analysis of individual patient data Advanced Bladder Cancer (ABC) Meta-analysis Collaboration. Eur Urol. 2005;48(2):189-199; discussion 199-201.

22. Lane BR, Smith AK, Larson BT, et al. Chronic kidney disease after nephroureterectomy for upper tract urothelial carcinoma and implications for the administration of perioperative chemotherapy. Cancer. 2010;116(12):2967-2973.

23. Kaag MG, O’Malley RL, O'Malley P, et al. Changes in renal function following nephroureterectomy may affect the use of perioperative chemotherapy. Eur Urol. 2010;58(4):581-587.

24. Hussain AE, Blakley BW, Nicolas M, Balderston J. Assessment of the protective effects of amifostine against cisplatin-induced toxicity. J Otolaryngol. 2003;32(5):294-297.

25. Ersoy H, Yaytokgil M, Karakoyunlu AN, Topaloglu H, Sagnak L, Ozok HU. Single early instillation of mitomycin C and urinary alkalinization in low-risk non-muscle-invasive bladder cancer: a preliminary study. Drug Des Devel Ther. 2013;7:1-6.

26. Xylinas E, Rink M, Margulis V, et al; UTUC Collaboration. Impact of renal function on eligibility for chemotherapy and survival in patients who have undergone radical nephro-ureterectomy. BJU Int. 2013;112(4):453-461. 


\section{Publish your work in this journal}

Drug Design, Development and Therapy is an international, peerreviewed open-access journal that spans the spectrum of drug design and development through to clinical applications. Clinical outcomes, patient safety, and programs for the development and effective, safe, and sustained use of medicines are a feature of the journal, which has also been accepted for indexing on PubMed Central. The manuscript management system is completely online and includes a very quick and fair peer-review system, which is all easy to use. Visit http://www.dovepress.com/testimonials.php to read real quotes from published authors.

Submit your manuscript here: http://www.dovepress.com/drug-design-development-and-therapy-journal 